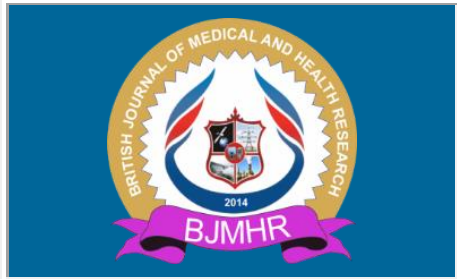

\title{
BJMHR
}

British Journal of Medical and Health Research

Journal home page: www.bjmhr.com

\section{Ultrasound in early Pregnancy by Village Midwives in Sudan}

\author{
Alsawi YA Yusuf ${ }^{1 *}$, Khidir E Awadalla ${ }^{2}$ \\ 1.Department of Radiology, University of Kordofan, Sudan \\ 2. Department of Obstetrics and Gynecology, University of Kordofan, Sudan.
}

\section{ABSTRACT}

Antenatal care services are provided by village midwives in rural communities in Sudan.Village midwives are well trained in the detection of pregnancy complications in late pregnancy. Ultrasound is an essential and safe tool in managing pregnancy in modern obstetric practice. However, in low-resource countries, the technique is not widely available. The aim of this pilot study was to systematically train village midwives to use ultrasound in the evaluation of early pregnancy. Midwives working in 20 villages were invited to participate in the study. Thirty-seven of them joined the study. They were enrolled in a two-weeks training programme. The training contained basic knobology, scanning techniques, sonographic anatomy and ultrasound appearances in early pregnancy using a portable machine. Patients with amenorrhea less than 12 weeks were included in the study population. Patients were first scanned by the principal investigators, midwives then scanned the patients and recorded their findings on a structured form. Patients mean age was 27 years $+/$ - 3.6, range 17 - 41 years. Nine of the patients were not pregnant, and 4 women had twins. A variety of pregnancy problems were identified including 13 missed abortions, 8 threatened abortions, 4 incomplete abortions, 2 molar pregnancies and one ectopic pregnancy. There were 378 patients with a viable intrauterine singleton pregnancy. Menstrual dates were confirmed in 297 (78.6\%) while in 81 $(21.4 \%)$ the dates were changed. Midwives recognized normal maternal anatomy in $100 \%$ of patients. The rates of true-positive for detection of presence of fetus and viability ranged between 81.9 to $100 \%$. Sensitivity for the diagnosis of molar pregnancy and ectopic pregnancy was $13.5 \%$ and $2.7 \%$ respectively. After a short training, village midwives could reliably confirm the presence/absence of pregnancy, viability and number of gestations. They could accurately measure and estimate gestational age in the first trimester, determine the location of the placenta and recognize when patients should be referred for specialist care.

Keywords: obstetric ultrasound, midwives, maternal mortality, early pregnancy.

*Corresponding Author Email: Alsawi1@ yahoo.com

Received 05 December 2020, Accepted 22 Decembers 2020

Please cite this article as: Alsawi YA et al., Ultrasound in early Pregnancy by Village Midwives in Sudan. British Journal of Medical and Health Research 2020. 


\section{INTRODUCTION}

Ultrasound has become an indispensible tool in managing pregnancy in modern obstetric practice. ${ }^{(1)}$. In developed countries, pregnant women routinely have pregnancy confirmed by ultrasound, have anatomic surveys in the midtrimester and ultrasound examinations in the third trimester if there are concerns about fetal size. With current protocols, accurate dating and early detection of abnormal pregnancy is possible. However, in low-income countries, the technique is not widely available due to lack of trained health personnel and the high cost of equipment $(2,3)$.

Ultrasound use has a proven positive impact on the clinical decision making in obstetric as well as general medical care ${ }^{(4,5)}$. Although some studies suggested that the use of ultrasound by midwives and nurses may lead to medicalization of pregnancy ${ }^{(6)}$, other studies suggested that US significantly benefits obstetric care in the developing world and guides patient management plans ${ }^{(7)}$. With high pregnancy-associated morbidity and mortality in these settings and the rapidly decreasing cost of ultrasound equipment, it is currently possible for rural midwives to have access to ultrasound equipment ${ }^{(8)}$. In the Sudan, midwives are found in every village, unlike physicians, who tend to practice in larger towns and cities.

The aim of this pilot study was to train village midwives who had no prior experience with ultrasound with a systematic curriculum of didactics and supervised hands-on scanning, to evaluate women for early pregnancy complications. The performance of these midwives was thereafter assessed in their local patients.

\section{METHOD}

Midwives who practiced in the 20 villages of the Damira District, West Bara locality North Kordofan State, Sudan, were invited to participate in the study. Thirty-seven midwives agreed and joined the study. No midwife had previous experience with ultrasound. Ethical as well as administrative clearance was obtained from the State Health Board and from the Research Ethics Committee of the University of Kordofan.

A two weeks training course was organized at the Damira Health Center (DHC). Basic knobology, scanning techniques, maternal sonographic anatomy and normal and abnormal findings associated with early pregnancy were demonstrated in theoretical and hands-on sessions. We used the chapter on first trimester ultrasound from an on-line text ${ }^{(9)}$ as a basis for the training material, tailoring the material to the educational level of the midwives and translating it into Arabic. A portable, battery-operated US machine costing less than 1000 US\$ (Mindray DP-10, Shenzhen, China) with a $3.5 \mathrm{MHz}$ convex abdominal probe was used for the "hands-on" portion of the course. From January 7 to February 27, 2018 all patients presenting for antenatal care at 5 primary healthcare centres in the District were referred for ultrasound 
at DHC. Those with amenorrhea less than 12 weeks were included in the study. The principal investigators reviewed the cases together and documented the findings. Midwives then scanned the patients and recorded their findings on a structured form. Data was analyzed using a freely available, open-source statistical software package (PSPP, GNU.org).

\section{RESULTS}

Four-hundred nineteen patients, mean age 27 years +/ - 3.6, range 17- 41 years, were scanned. Nine of them were not pregnant and 4 had twins. Patients with a viable, singleton and intrauterine gestation were 378 (90.2\%). Menstrual dates were confirmed in 297 (78.6\%) of the patients, while in $81(21.4 \%)$ the dates were changed. Findings in the whole group are shown in Table 1. Midwives recognized normal maternal anatomy (bladder, cervix and uterus) correctly in $100 \%$ of patients. The rates of true-positive (sensitivity) for detection of presence of intrauterine gestation sac and fetus, signs of viability (cardiac pulsations), estimation of gestational age (GS and CRL), location of placenta and twin pregnancy are shown in Table 2. Sensitivity for the diagnosis of molar pregnancy and ectopic pregnancy was $13.5 \%$ and $2.7 \%$ respectively.

Table 1: Ultrasound Findings in patients with Amenorrhoea less than 12 weeks

\begin{tabular}{lll}
\hline Finding & Number & Per cent \\
\hline Not pregnant & 9 & $2.1 \%$ \\
Normal viable singleton pregnancy & 378 & $90.2 \%$ \\
Missed abortion & 13 & $3.1 \%$ \\
Threatened abortion & 8 & $1.9 \%$ \\
Incomplete abortion (retained products) & 4 & $1 \%$ \\
Twins & 4 & $1 \%$ \\
Molar pregnancy & 2 & $0.5 \%$ \\
Right tubal ectopic pregnancy & 1 & $0.2 \%$ \\
Total & 419 & $100 \%$ \\
\hline
\end{tabular}

Table 2: Sensitivity of US findings by village midwives in early pregnancy

\begin{tabular}{lc}
\hline Category & Sensitivity \\
\hline Recognition of normal maternal anatomy & $100 \%$ \\
Detection of GS and fetus & $96.6 \%$ \\
Detection of viability (heart beat) & $97.1 \%$ \\
Estimation of gestational age & $93.3 \%$ \\
Location of placenta & $89.2 \%$ \\
Missed abortion & $87.3 \%$ \\
Incomplete abortion (retained products) & $81.9 \%$ \\
Twin pregnancy & $100 \%$ \\
Molar pregnancy & $13.5 \%$ \\
Ectopic pregnancy & $2.7 \%$ \\
\hline
\end{tabular}

In $81(21.4 \%)$ of patients the dates were changed following ultrasound estimation of gestational age by GS or CRL. Thirty two $(7.7 \%)$ of the patients were found to have a pregnancy complication, when missed, threatened, incomplete abortions, twins, molar pregnancies and ectopic pregnancies were identified. An additional 9 patients $(2.1 \%)$ proved not to be pregnant 
and were referred for evaluation of amenorrhea. Overall, serious pregnancy complications which could potentially result in maternal morbidity and mortality were found in 32 ( $7.8 \%)$ patients. Overall, midwife trainees identified ( 81.9 - 100\%) of pregnancy complications. These women were referred for specialist consultation.

\section{DISCUSSION}

This study reported on outcomes after structured training in a small group of midwives in one district in the Sudan. The training was short, compared to that reported elsewhere ${ }^{(10,11)}$. We have demonstrated that village midwives can be trained to use ultrasound in early pregnancy to guide decision making after a two-week structured course consisting of classroom didactics and "hands-on" training on an inexpensive, portable ultrasound system. Midwives were found to be capable of identifying normal maternal structures, estimating gestational age, diagnosing twins, and identifying abnormal pregnancies, including missed, threatened and incomplete abortions, although molar pregnancies and ectopic pregnancy proved difficult for most of them. These findings are similar to results reported by other investigators in similar low-resource regions ${ }^{(10,12)}$.

The introduction of ultrasound services in rural communities would be an effective step in reducing maternal and fetal morbidity and mortality.

Further studies should focus on use of ultrasound by midwives in the second and third trimester, including pre- and intra-partum US in this region. However, some studies reported a tendency to normalize findings ${ }^{(13)}$ and a low sensitivity to detect anomalies ${ }^{(14)}$. Other studies reported a third trimester estimation of fetal weight by midwives as feasible and accurate. ${ }^{(15)}$. However, guidelines should be developed and more rigorous studies should be done, as some studies have flaws and limitations. ${ }^{(16)}$

\section{REFERENCES}

1. Gracia J, Bricker L, Henderson J et al. Women's Views of Pregnancy Ultrasound: A Systematic Review. BIRTH 2002; 29(4):225-250.

2. Brunette W, Hicks M, Hope A, Ruddy G, Anderson RE, Kolko B. Reducing Maternal Mortality: An Ultrasound System for Village Midwives. In Global Humanitarian Technology Conference (GHTC), 2011.

3. Brunette W, Gerard W, Hicks MA, et al. Portable antenatal ultrasound platform for village midwives. In Proceedings of the 1st ACM Symposium on Computing for Development, DEV 2010.

4. Spencer JK, Adler RS: Utility of portable ultrasound in a community in Ghana. $J$ Ultrasound Med 2008, 27(12):1735-1743.

5. Blaivas M, Kuhn W, Reynolds B, Brannam L: Change in differential diagnosis and 
patient management with the use of portable ultrasound in a remote setting. Wilderness Environ Med 2005, 16(1):38-41.

6. Edvardsson K, Mogren I, Lalos A, Persson M, Small R. A routine tool with far-reaching influence: Australian midwives' views on the use of ultrasound during pregnancy. $B M C$ Pregnancy and Childbirth 2015; 15:195.

7. Shah SP, Epino H, Bukhman G, et al. Impact of the introduction of ultrasound services in a limited resource setting: rural Rwanda 2008. BMC International Health and Human Rights 2009; 9:4.

8. Sippel S, Muruganandan K, Levine A, Shah S. Use of ultrasound in the developing world. International Journal of Emergency Medicine; 2011 4:72.

9. Abuhamad A (Ed.). Ultrasound in Obstetrics and Gynecology: A Practical Approach. West Virginia Medical School; 2014. E-book, www.wvms.edu.

10. Kimberly H, Murray A, Mennicke M, et al. Focused Maternal Ultrasound by Midwives in Rural Zambia. Ultrasound in Medicine and Biology 2010; 36(8):1267-1272.

11. Gegor CL. Third Trimester ultrasound for nurse midwives. Journal of Midwifery \& Women's Health 1993; 38(S1):49s-61s.

12. Swanson JO, Kawooya MG, Swanson DL, Hippe DS, Dungu-Matovu P, Nathan R. The diagnostic impact of limited screening obstetric ultrasound when performed by midwives in rural Uganda. Journal of Perinatology 2014; 34:508-512.

13. Capmas P, Salomon L J, Picone O, Fuchs F, Frydman R, Senat, MV. Using Z-scores to compare biometry data obtained during prenatal ultrasound screening by midwives and physicians. Prenat. Diagn., 30: 40-42.

14. Eurenius K, Axelsson O, Cnattingius S, Eriksson L, Norsted T. Second trimester ultrasound screening performed by midwives; sensitivity for detection of fetal anomalies. Acta Obstet Gynecol Scand 2009; 78(2):98-104.

15. Mattsson N, Rosendahl H, Luukkaala T. Good accuracy of ultrasound estimations of fetal weight performed by midwives. Acta Obstet Gynecol Scand 2007; 86(6):688-692.

16. Neto MAC, Roncato P, Nastri CO, Martins WP. True Reproducibility of UltraSound Techniques (TRUST): systematic review of reliability studies in obstetrics and gynecology. Ultrasound Obstet Gynecol 2015; 46(1):14-20.

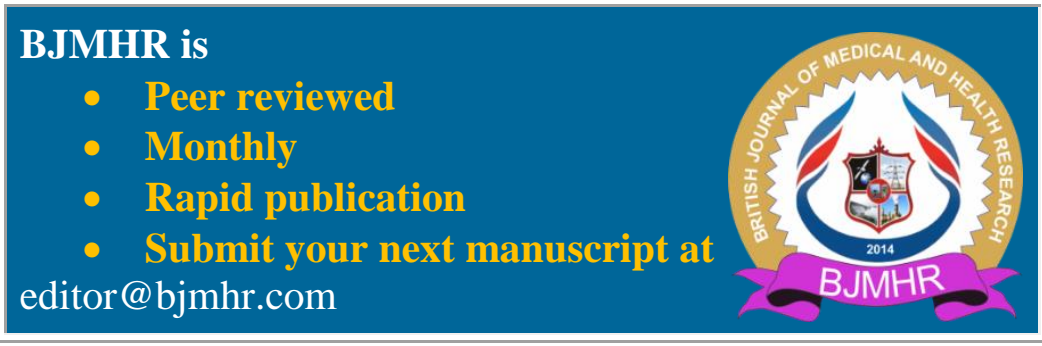

